\title{
EFFECTS OF LEADERSHIP ROLES ON TEAM EFFECTIVENESS*
}

\author{
Assist.Prof. Dr. Ethem Duygulu, Dokuz Eylül University, Faculty of Economics \\ and Administrative Sciences, Department of Business Administration, \\ ethem.duygulu@deu.edu.tr \\ Dr. Nurcan Çıraklar, Dokuz Eylül University, Faculty of Economics and \\ Administrative Sciences, Department of Business Administration, \\ n.ciraklar@deu.edu.tr
}

\begin{abstract}
In this study we aim to explain the patterns of leadership roles for team effectiveness in non profit organizations compared to economic organizations. For this purpose, we studied three successful organization types, i.e the amateur sports clubs (football, basketball), theater companies and, regional folk groups. Our basic hypothesis is that the relationship between the type of organization (specially teams) and the role of leadership is not random. Therefore, we believe that an empirical approach is necessary to test the assumptions about leadership and team effectiveness. Also these empirical results are supposed to lead to professional managers in economic organizations. First, we constructed thirteen key dimension variables for leadership behavior as follows: coaching, effective communication, encouraging teamwork, establishing high standards and getting results, effective delegation, rewarding performance, developing and releasing employees, building consensus, supporting reasonable risk- taking, forecast thinking, improving the organization, managing diversity, and overall effectiveness. Second, we defined team standards and effectiveness in twenty items. And finally, we tried to emphasize factors affecting leadership roles and team effectiveness. In this study, Natemeyer and Babko (1992) Management Practices Survey data are used. Data reliability are tested before the analysis and results are discussed at the end of the study.
\end{abstract}

Keywords: Team effectiveness, Leadership Roles

\footnotetext{
* This paper was presented by European Applied Business Research Conference in ItalyVenice, June, 2003.
} 


\section{INTRODUCTION}

Mullins (1996) defines leadership as a relationship through which one person influences the behavior of other people (Kangis and Kelly;2000: 393). Leaders must not only be able to define departmental, unit or organizational missions, but they must also be able to coordinate the activities of others and motivate them to meet mission requirements. Additionally, they must circumvent or resolve issues impeding progress towards accomplishing organizational goals. Selection and implementation of actions to bring about goal attainment represents a form of problem solving which makes the generation, evaluation, and implementation of proactive and reactive solutions key to leader effectiveness (Mumford et al, 2000 :14). With respect to understanding effective leadership in organizational settings however, the nature of the problems at hand and their associated performance demands have another remarkable set of implications. Specifically, they provide us with some important clues about the type of knowledge and skills likely to underlie effective performance in organizational settings (Mumford et al., 2000:15). Leaders must not only be able to formulate a plan that works within the context of organization, they must also be able to implement this plan within a distinctly social context, marshaling support, communicating a vision, guiding subordinates, and motivating others. Thus, leaders must be able to understand and work with others, another point which underscores the need for social skills (Mumford et al,2000:19).

The study of leadership which concerns the nature of superior and subordinate relationship encompasses various approaches, such as trait theory, behavioral theory, and contingency theory (Robbins, 1998;344-388). The traditional leadership studies adopted two approaches: Traits and behavioral approaches. According to traits approach, most of the previous research based on this, a leader can simply direct his/her members for organizational goals thanks to his/her psychical or psychological characteristics. Meanwhile, these studies of leadership assumed that a leader possesses characteristics or traits that distinguish him/her from followers, and this assumption serves as a basis for the trait theory of leadership. Several research in that period concentrated to identify a set of personality traits, such as appearance, intelligence, selfreliance, and persuasiveness, to delineate great leadership, but they could not come up with a universal list of traits that all successful leaders possess (Diskul, 2001:42-43). In essence, this approach has not sufficiently explained leadership behavior. By the late 1940s, most of the leadership research had moved from what leaders were to what they did -the behavioral approach. On the other hand, behavioral approach suggests that effective leaders influence their fellow members thorough their behavior. These behaviors can be acquired and improved by training. It was assumed that effective leaders consistently used distinctive styles. Many studies attempted to identify the behavioral differences of effective leaders visa versa ineffective leaders. Both the traits and behavioral leadership theories tried to find a unique leadership style for all situations (Diskul, 2001:42). Well known studies on leadership behavior include Ohio State University Studies, University of Michigan State Studies and Blake and 
Mouton studies which is called Managerial Grid. The distinctive characteristics of these studies are generally splitting behavioral patterns as employee oriented and task oriented.

On the other hand, these studies in traits and behavioral approach failed to obtain consistent and significant results. This led to a change in focus towards situational factors (Contingency theory). However, it became apparent in the late 1960s that there is no unique leadership style for all situations. Thus, contingency theory or approach which assumes that the appropriate leadership style varies from situation to situation was developed to explain leadership phenomenon. The contingency theory of Fiedler (1967) suggests that whether a group is effective depends upon a proper match between leader's style of interaction with members and the degree to which the situation gives control and influence to the leader (Cheung et al, 2001:421-422). According to this approach, situational factors, which may include the leader's authority, the relationship between the leader and the member, the type and nature of work and characteristics of the subordinates should be in harmony with the leadership behavior. The situational approach treats leadership effectiveness as arising from the dynamic interplay of three factors: the leader, the followers and the situation in which they all take part (Kangis and Kelley., 2000: 394). Nevertheless, the contingency approach still falls short serving as a general theory of leadership. Thus, it could be summed up that none of the trait, behavioral, and contingency approaches are sufficient to explain leadership alone (Diskul, 2001:43). Therefore we accepted that the relationship between leadership roles and team effectiveness have to interact. Leaders have an influence on both members' attitude and work situation, and they also affected by the team member's attitude and working situations at the same time.

As mentioned above there is a constant interaction between the leader and the team. There is also interaction between team members. Therefore, a team should be defined as an active unit. According to Buchlozs, Roth and Hess (Garner, 1998:3) "wearing the same shirt does not make a team". Morgan, Glickman, Woodard and Salas define a team as "distinguishable set of two or more individuals who interact interdependently and adaptively to achieve specified, shared and valuable objectives". This definition is useful because it shows that a team is comprised of people. These people proceed to act interdependently, and the interaction of people contributes the team to achieve some specified goal (Garner,1998: 5). Another definition of team according to Katzenbah and Smith (1991) is "a team is a small number of individuals associated in some joint action, with a strong, deep seated, common sense of purpose" (Garner, 1998:5). Team members are mutually committed, mutually supportive, and collectively responsible for the achievement of team goals and objectives. Real teams create synergy; they perform at levels above that of groups. Team members work closely and freely with each other to achieve their common performance goals. Real teams perform tasks that cannot be achieved by individuals alone (Garner,1998: 12-13). 
Sundstrom and Associets (1999) state that effectiveness of teams start with meeting the performance expectations, of those who receive, use, or review the team's output. Performance expectations usually stem from managers, internal and external customers, and others. Performance expectations differ depending on groups receiving services. For example, a customer usually expects quality, timeliness, low cost, and responsiveness of service. Manager expects that a team will meet customer's expectations and that they will be productive (Anqelique, 2001:7-8). Other expectations which affect team's efficiency are related to employee behavior and quality of work life. On the other hand, task variety, task identity, task significance, task autonomy, and task feedback can contribute team effectiveness. Team composition like heterogeneity, team stability and team size are also contributing factors to team's efficiency. Heterogeneity has a positive impact on team effectiveness, especially when a task assigned to a team is diverse (Diskul, 2001:13). Team stability involves the continuity of membership. A stable team can provide its members security through knowledge of expectations, and belief systems. It also has cohesive team values which promote team effectiveness and satisfaction. Furthermore, team size can affect team functioning and create problems such as complicating communication and coordination. It is suggested that team size should be limited to a minimum number in accordance with team's goals. If a team is too large, the quality of interaction between its member's decreases and this impairs team effectiveness which results in high costs and process losses (Diskul, 2001:13-15). Team beliefs and members' involvement are also important factors for team effectiveness. In the relevant literature, effective and ineffective teams are characterized by several factors (Viveiros, 1999:37-38). Table 1 shows these factors. Team effectiveness has been studied in relation to the team performance. Snee points out that both the team members' and the team leader's efforts are necessary if there is to be an effective team. Snee also claims that a common terminology is a skill developed over time, a skill must be practiced and learned (Dewald, 2002:21). Larson and La Fasto have identified eight dimensions that are regularly associated with team excellence. These dimensions are clear goals, results driven structure, competent team members, unified commitment, collaborative climate, standards of excellence, external support and recognition and principled leadership (Dewald, 2002:2122).

Table1: Effective and Ineffective Team Characteristics

\begin{tabular}{|l|l|}
\hline Effective Team Characteristics & Ineffective Team Characteristics \\
\hline Clear goals that all group members committed & Formal and tense interactions \\
\hline Open, honest communication & Poor communication \\
\hline Cooperative decision-making & Hierarchical Structures \\
\hline An atmosphere of trust & Low trust levels \\
\hline A sense of belonging & Role confusion \\
\hline Good listening skill & Unclear team mission \\
\hline Participation by all members & Lack of cooperation among members. \\
\hline
\end{tabular}


Larson and LaFasto state that clarity of goal is critical for team members. This clarity insures that the members have confidence in the direction of the goal. Taborda said that, "effective teams invest a great amount of time effort exploring and agreeing on the purpose that gives them direction. In contrast, failed teams rarely develop a common purpose" (Dewald, 2002:22). Managers in all types of organizations use some variation of the dimension, clear elevating goal. This dimension particularly evidenced in the Management by Objectives concept. In this concept, the leader and team members identify the goals, define the members' roles and expectations of the roles and then if the members contribute to meet these goals. Priorities have been set and agreed upon by both the members and team leader (Dewald, 2002:22). According to this interpretation, leaders play an important role to compose effectiveness in a team.

\section{RESEARCH DESIGN}

According to Jiang and others (1997:237), team effectiveness can be evaluated using objective or subjective measures. Because objective measures usually miss certain critical factors, there appears to be agreement across studies in the choice of subjective measures, with many studies using scales that combine satisfaction measures with measures of teams' ability to achieve their goals. Effective teamwork is achieved when members of a team work together in such a way that core goals are accomplished. Based on Jiang and others explanation to analyze team effectiveness: we used Natemeyer and Babkos' (1992) Management Practice Survey data questionnaire cited in Samawicz (1998).

According to Grendstad and Strand (1999:389) the number of possible leadership roles will be limited to four: namely producer, administrator, integrator and entrepreneur which reflect the widespread agreement among scholars about the basic functions identifiable in any organization. The measurement of roles reflects a rather ambiguous definition of the concept, i.e. the individuals' assessment based on their position, their perception of the expectations or demands according to the roles, their perception of their own performance efficacy and the perception of their role performance by other significant people.

Leadership roles are difficult to evaluate yet it can be expressed by leader's behavior. Leaders displaying leadership behavior can increase the level of satisfaction of the team members and improve the performance of the team (Cheung et al, 2001:422). These roles can be changed by organization culture and orientations of "production-centered" or "employee-centered". This research seeks to establish a relationship between leadership roles and team effectiveness. Meanwhile, the present study contains a number of variables that are not reported in this paper, such as culture, control and several individual and organizational characteristics. But we accepted that organizational factors and others play an important role in determining whether or not a team is effective. 
For example, Zack and Serino (1996) describe a competitive or collaborative culture as one such component that can enhance or hinder team functioning (Viveiros, 1999:34). When rules, however, are unknown and ambiguous, and are based on a rigid hierarchical power structure, teams can become ineffective. Further, established norms provide rewards and sanctions and define how teams accomplish its tasks. And finally, the social structure of the organization both formal and informal can promote or stifle communication, collaboration, trust, conflict resolution, and mutual respect, thus has an impact on team effectiveness (Viveiros, 1999:33).

Figure 1: Relationship between Team Effectiveness and Leadership Roles

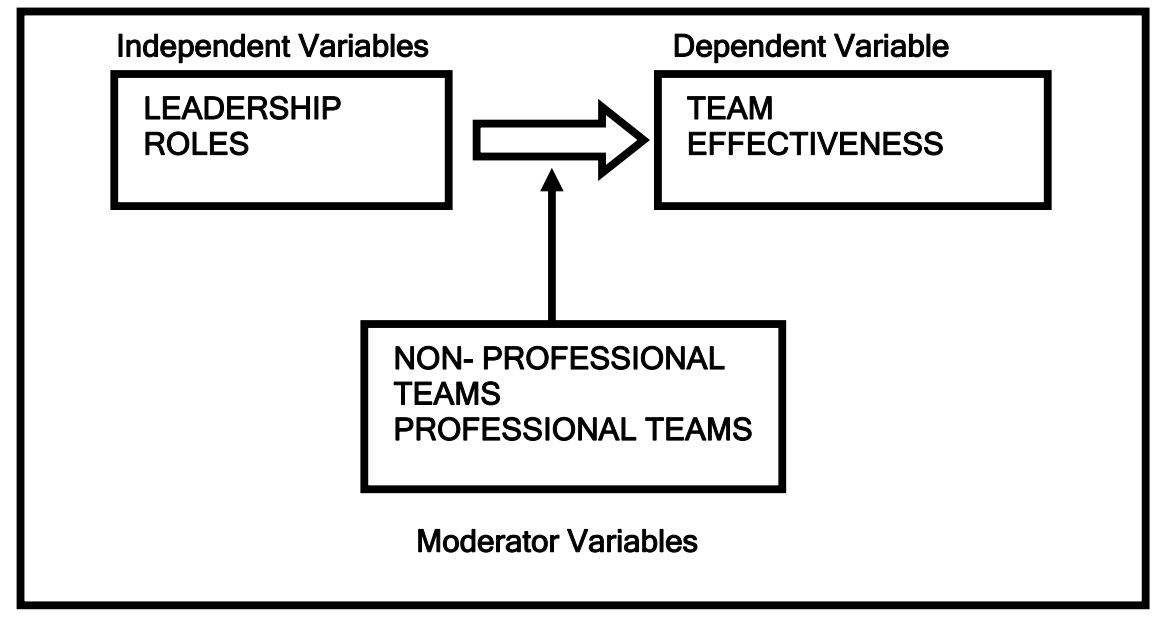

According to the model, leadership roles are assessed in thirteen subdimensions. These dimensions which are accepted as independent variables are coaching, effective communication, encouraging teamwork, establishing high standards, effective delegation, rewarding performance, developing and releasing employees, building consensus, supporting reasonable risk taking, forecast thinking, improving the organization, managing diversity, and overall effectiveness (Samawicz,1998:128 ). On the other hand, team effectiveness is chosen as dependent variable. The dependent variable is affected by the perceptions of non-professional and professional participants so we used a moderator to explain this relationship.

\subsection{Questionnaire and Statistical Method}

The questionnaire is comprised of three major sections. These sections are Leadership roles, team effectiveness and sample's demographic characteristics respectively. Thirteen sub-dimensions are used to assess leadership roles and these dimensions include fifty statements for measurement. Total alpha level for those statements is 0.97 . Team effectiveness dimension includes twenty items and alpha level for this statement is 0.95 . These findings for alpha levels are 
very high reliability and acceptable. Final section of questionnaire is arranged with respect to research aims. Genders, age, level of education, profession, experience and team membership period are identified in this section.

A five-point Likert scale is used to measure each dimension. To measure leadership roles, participants are asked to indicate "don't apply" or "apply" with each statement on five point Likert scale, from "never apply" to "certainly apply". On the other hand to measure team effectiveness, respondents are required to indicate their degree of agreement or disagreement with each item on the scale, from strongly disagree to strongly agree. Descriptive statistics are computed to develop a profile of the sample and regression analysis (stepwise method) used between dependent and independent variables for causality. To show how independent variables affect dependent variable, a moderator, professional and nonprofessional, is used.

\subsection{Data Collection}

The sample in this study was chosen randomly between non-economic and economic goal teams. Non economics sample was included football and volleyball teams, Theatre workers and Folk dance team members. Economic goal team members were chosen from industry. A research questionnaire was administered for 152 team members and total 149 usable responses were received. This yields a usable response rate of 98 percent. The Frequency distributions of teams are given in Table 2. 56 (37.6 percent) of the respondents were female and 53 (35.6 percent) were male. 40 (26.8 percent) did not mark the gender question.

Table 2: Frequency Distributions of Team Members ( $n=149)$

\begin{tabular}{|c|c|c|c|c|c|}
\hline Team composition & $\begin{array}{l}\text { Football } \\
\text { (n/ } \\
\text { percent) }\end{array}$ & $\begin{array}{l}\text { Volleyball } \\
\text { (n/percent) }\end{array}$ & $\begin{array}{l}\text { Folk } \\
\text { Dance } \\
\text { (n/ } \\
\text { percent) }\end{array}$ & $\begin{array}{l}\text { Theatre } \\
(\mathrm{n} / \\
\text { percent) }\end{array}$ & $\begin{array}{l}\text { Manufactory } \\
\text { (n/percent) }\end{array}$ \\
\hline Non-professional & $11(7.5)$ & $5(5.3)$ & $36(24.2)$ & $\begin{array}{ll}45 & (30.2) \\
\end{array}$ & -------- \\
\hline Professional & $1(0.6)$ & $4(4.1)$ & $4(2.6)$ & ------- & $38(25.5)$ \\
\hline
\end{tabular}

The average age was less than 23 years and this included 107 (71.8 percent) of the participants in the sample. As for the educational level, most of the participants graduated from high school (104 and 69,8 percent) and at the same time some of these participants continue their university education. On the other hand participants time period of team membership were 19.5 percent (29) less than one year, 29.5 percent were member of team for one year, 16.1 percent spent on time in a team for two years and others were 14.1 percent more than three years experienced. The 31 participants were not points out about time experience in a team. For the total samples 52 participants were professional and 97 participants were amateur in the teams. 


\subsection{Findings}

To examine the relationship between leadership roles and team effectiveness, stepwise regression analysis was conducted. Two groups, non-professional and professional, are used as moderator to find the causality between these variables. There are not any significant differences between male and female members' perceptions of both team effectiveness and leadership roles. Furthermore, managing diversity dimension between professionals and nonprofessionals is statistically significant at the level of 0.001 , and the other dimensions do not have any statistically significant relationship. With respect to correlation analysis findings, leadership roles and team effectiveness variables are significantly correlated to each other. Table 3 shows these findings.

Table 3: Correlation Findings for each Dimension

\begin{tabular}{|c|c|}
\hline Leadership Roles & Team Effectiveness $\quad(n=149)$ \\
\hline Coaching & $.569^{\star *}(125)$ \\
\hline Effective Communication & $.659 * *(128)$ \\
\hline Encouraging Team work & $.654^{* *}(126)$ \\
\hline Establishing High Standard & $.608^{* *}(126)$ \\
\hline Effective Delegation & $.691^{\star *}(125)$ \\
\hline Rewarding Performance & $.403^{* *}(127)$ \\
\hline Developing \& Releasing Employees & $.586^{\star *}(125)$ \\
\hline Building Consensus & $.567^{* *}(129)$ \\
\hline Supporting Reasonable Risk-taking & $.614^{\star \star}(127)$ \\
\hline Forecast Thinking & $.730^{\star *}(126)$ \\
\hline Improving the Organization & $.620 * *(128)$ \\
\hline Managing Diversity & $.679^{* *}(128)$ \\
\hline Overall Effectiveness & $.720^{\star \star}(127)$ \\
\hline
\end{tabular}

Correlation is significant at the 0.01 level (1-tailed)

These findings support that there exists a relationship between leadership roles and team effectiveness. In other words, leader's role in helping the team to clarify, define or manage a goal can not be overlooked.

In step 1, managing diversity was regressed on team effectiveness and the team effectiveness Beta weight was significant $(\beta=0.58)$, $t$ value is statistically significant $(.000)$.

In step 2, when building consensus was added to the leadership roles, the Beta weight for team effectiveness was negative and significant $(\beta=-0.375$, $t$ value is less than 0.05). On the other hand a significant increase in $R^{2}$ was found $\left(F=11.732, R^{2}=.401\right)$ when effective delegation was entered into the model 3 at the third step $\left(F=11.241, R^{2}=.49\right)$. Beta weight for team effectiveness in model 3 was statistically significant. According to this result, managing diversity in the leadership roles is the strongest explanatory variable to explain team effectiveness for professionals. But these results are different for non- 
professionals when used as a control variable for professionals. Table 5 shows these differences.

Table 4: Results of the Regression Analysis for the Effects of Leadership Roles on Team Effectiveness in Professionals ( $n=52)$

\begin{tabular}{|c|c|c|c|c|c|c|}
\hline $\begin{array}{c}\text { Independent } \\
\text { Variables Entered }\end{array}$ & $\beta$ & $\mathrm{t}$ & Sig. & Adj. R2 & $\mathrm{F}$ & Sig. \\
\hline Model 1 & & & & 0.318 & 15.918 & .000 \\
Managing & 0.582 & 3.990 & .000 & & & \\
Diversity & & & & & & \\
\hline Model 2 & & & & 0.401 & 11.732 & .000 \\
Managing & 0.785 & 4.831 & .000 & & & \\
Diversity & -0.375 & -2.307 & .028 & & & \\
Building & & & & & & \\
Consensus & & & & & \\
\hline Model 3 & & & & 0.490 & 11.241 & .000 \\
Managing & 0.584 & 3.429 & .002 & & & \\
Diversity & -0.392 & -2.610 & .014 & & & \\
Building & 0.378 & 2.489 & .019 & & & \\
Consensus & & & & & & \\
Effective & & & & & & \\
Delegation. & & & & & \\
\hline
\end{tabular}

Moderator: Professional

The regression analysis findings in Table 5 , the adjusted $R$ square $\left(R^{2}\right)$ indicates that the percentage of total variance of team effectiveness by the leadership roles (.86) dimensions of the forecast thinking, managing diversity, effective communication, and rewarding performance. According to this result, forecast thinking is the strongest explanatory variable in the leadership roles $\left(R^{2}=0.73\right)$ to explain team effectiveness for the non-professionals. These subdimensions of leadership roles' $t$ value for the first step is 14.119 and $F$ value is 199.354 and this value is statistically significant. The next independent variable with the highest t-value is managing diversity in the leadership roles. For the last step, other independent variables (effective communication and rewarding performance) were also entered into the analysis. On the other hand, the relationship between rewarding performance and team effectiveness for the non-professionals has a negative slope. The regression beta value of forecast thinking decreased from 0.86 to 0.383 as $R^{2}$ rose from 0.73 to 0.86 when the other independent variables entered into the analysis. 
Table 5: Results of the Regression Analysis for the Effects of Leadership Roles on Team Effectiveness in Non-professional Teams ( $N=97)$ (stepwise method)

\begin{tabular}{|c|c|c|c|c|c|c|}
\hline $\begin{array}{l}\text { Independent } \\
\text { Variables Entered }\end{array}$ & $\beta$ & $t$ & Sig. & Adj. R2 & $\mathrm{F}$ & Sig. \\
\hline $\begin{array}{l}\text { Model } 1 \\
\text { Forecast Thinking }\end{array}$ & 0.860 & 14,119 & .000 & 0.736 & 199.354 & .000 \\
\hline $\begin{array}{l}\text { Model } 2 \\
\text { Forecast Thinking } \\
\text { Managing Diversity }\end{array}$ & $\begin{array}{l}0.500 \\
0.472\end{array}$ & $\begin{array}{l}6.564 \\
6.200\end{array}$ & $\begin{array}{l}.000 \\
.000\end{array}$ & 0.828 & 172.221 & .000 \\
\hline $\begin{array}{l}\text { Model } 3 \\
\text { Forecast Thinking } \\
\text { Managing Diversity } \\
\text { Effective Commun. }\end{array}$ & $\begin{array}{l}0.349 \\
0.379 \\
0.280\end{array}$ & \begin{tabular}{|l|}
4.217 \\
5.009 \\
3.483
\end{tabular} & $\begin{array}{l}.000 \\
.000 \\
.001\end{array}$ & 0.852 & 137.379 & .000 \\
\hline $\begin{array}{l}\text { Model } 4 \\
\text { Forecast Thinking } \\
\text { Managing Diversity } \\
\text { Effective Commun. } \\
\text { Rewarding Perform. }\end{array}$ & $\begin{array}{l}0.383 \\
0.405 \\
0.283 \\
-0.116\end{array}$ & $\begin{array}{l}4.678 \\
5.442 \\
3.626 \\
-2.239\end{array}$ & $\begin{array}{l}.000 \\
.000 \\
.001 \\
.029\end{array}$ & 0.860 & 110.365 & .000 \\
\hline
\end{tabular}

Moderator: Non professional

\section{CONCLUSION AND LIMITATIONS}

According to the regression results, managing diversity is a common explanatory variable for both professionals and non-professionals. Forecast thinking, effective communication, building consensus, effective delegation and rewarding performance variables differ between professionals and nonprofessionals. Forecast thinking, effective communication and rewarding performance are distinctive characteristics of non-professionals whereas building consensus and effective delegation are the characteristics of professionals. These findings lead us to think leadership roles are under the influence of organizational conditions i.e. management practice, working conditions, the perception of members and the characteristics of tasks. The second important findings are related with professional teams in organizations. They may perceive their organizational conditions as to be related to job permanence. So their aims can be attaining pre-established goals in order to maintain their job positions and wages also by considering hierarchical structure in their organizations. Achievement can be defined as championship for nonprofessional teams. Rather than financial reward recognition, self-actualization, and esteem can put weigh in those teams characterized by willingness of team members. For this reason it must be considered that leadership roles may be perceived differently by those two teams. The important point is the necessity of questioning how non-professional teams' success can be reflected to organizations. 
The first limitation of this study is revolved around the sample size. The method of data collection was difficult, as well as time consuming. All team members had to be present and had to complete the survey for the data to be considered as valid. Difficulties arose in scheduling and time constraints for teams, and even availability of team members as the entire team is never possible together at the same time. A larger sample might have supported the study's hypothesis more strongly.

\section{REFERENCES}

Anqelique Andrews B.S. (2001). Virtual Teams and Technology: The Relationship between Training and Team Effectiveness, Dissertation, University of North Texas, p. 71.

Cheung S.O, Thomas N. S., Lam K.C., and Yue W.M.(2001). A Satisfying Leadership Behavior Model for Design Consultants, International Journal of Project Management, 19, p. 421-429

Dewald Sherry L. (Messina) (2002). Collaborative Leadership in Law Enforcement Teams, Dissertation, University of Denver, p. 166.

Diskul, Pajita (2001). Toward Effective Self-managing Work Teams (SMWTs): The Relationship between Perceived Leadership Styles and SMWT Characteristics. Dissertation, Virginia Commonwealth University Richmond, Virginia, p. 266.

Garner C., L.,(1998): Team Building and Organizational Effectiveness, Dissertation, The University of Texas at Austin. p. 210.

Grendstad Gunnar , Strand Torodd (1999). Organizational types and leadership roles, Scandinavian Journal of Management, 15, p. 385-403

Jiang J. J., Motwani, J. and Margulis S. T. (1997). IS team projects: IS professionals rate six criteria for assessing effectiveness Team Performance Management, Vol. 3 No. 4, p .236-243.

Viveiros Marie Gail (1999). An Investigation into The Relationship between Effective Teams and Individual Team Member Behavior Patterns: A New Perspective on Organizational Functioning. Dissertation, University of Colorado at Denver., p. 183.

Mumford Michael D., Stephen J. Zaccaro, Francis D. Harding , T. Owen Jacobs and Edwin A. Fleishman (2000). Leadership Skills for a Changing World: Solving Complex Social Problems Leadership Quarterly, 11(1), p. 11-35.

Kangis, P, and Kelley, L. L., (2000): Project leadership in clinical research organizations, International Journal of Project Management, 18, p. 393-401 
Robbins, S.,(1998) :"Organizational Behavior: Concepts, Controversies, Applications", Prentice-Hall, USA

Samawicz Philip Stephen (1998). Cross-Cultural Team Building: The Impact of Leadership and Technology on an Industrial Project in West Africa, Dissertation, The Fielding Institute, p. 143. 